\title{
Association between use of contraband tobacco and smoking cessation outcomes: a population-based cohort study
}

\author{
Graham C. Mecredy MSc, Lori M. Diemert MSc, Russell C. Callaghan PhD, Joanna E. Cohen PhD
}

See related editorial by Stanbrook at www.cmaj.ca/lookup/doi/10.1503/cmaj.130377

\begin{abstract}
Background: High tobacco prices, typically achieved through taxation, are an evidencebased strategy to reduce tobacco use. However, the presence of inexpensive contraband tobacco could undermine this effective intervention by providing an accessible alternative to quitting. We assessed whether the use of contraband tobacco negatively affects smoking cessation outcomes.
\end{abstract}

Methods: We evaluated data from 2786 people who smoked, aged 18 years or older, who participated in the population-based longitudinal Ontario Tobacco Survey. We analyzed associations between use of contraband tobacco and smoking cessation outcomes (attempting to quit, $30-d$ cessation and longterm cessation at $1 \mathrm{yr}$ follow-up).

Results: Compared with people who smoked premium or discount cigarettes, people who reported usually smoking contraband ciga- rettes at baseline were heavier smokers, perceived greater addiction, identified more barriers to quitting and were more likely to have used pharmacotherapy for smoking cessation. People who smoked contraband cigarettes were less likely to report a period of 30-day cessation during the subsequent 6 months (adjusted relative risk [RR] 0.23, 95\% confidence interval [CI] 0.09-0.61) and 1 year (adjusted RR 0.30, 95\% Cl 0.14-0.61), but they did not differ significantly from other people who smoked regarding attempts to quit (at 6 mo, adjusted RR $0.74,95 \% \mathrm{Cl} 0.43-1.20$ ) or long-term cessation (adjusted RR $0.24,95 \% \mathrm{Cl}$ 0.04-1.34).

Interpretation: Smoking contraband cigarettes was negatively associated with shortterm smoking cessation. Access to contraband tobacco may therefore undermine public health efforts to reduce the use of tobacco at the population level.
I mplementing high tobacco prices, achievable through taxation, is an evidence-based strategy to reduce the use of tobacco. ${ }^{1,2}$ Among Canadian adults, a $10 \%$ increase in price is estimated to result in a decrease in cigarette demand of about $4 \% .^{2}$ However, the presence of cheap contraband - cigarettes sold without all appropriate taxes applied - undermines the potential health benefits of this effective intervention by providing an accessible alternative to quitting, ${ }^{3}$ increasing relapse and encouraging people to start smoking. ${ }^{4}$

The illegal sale of contraband cigarettes increased exponentially in Canada between 2002 and 2008, particularly in Canada's largest provinces, Ontario and Quebec..$^{5}$ In 2008, the contraband tobacco market in Ontario was estimated to be as much as $42 \%$ of total cigarette sales. ${ }^{5-7}$ Contraband cigarettes enter the Canadian market through 5 main sources: unlawfully or lawfully manufactured and smuggled in from the United States (mainly through First Nations reserves); unlawfully manufactured in Canada; tax-exempt products intended for sale to First Nations people but diverted to the general population; counterfeit products entering the country illegally; and other related criminality (e.g., thefts) ${ }^{6}$

As of 2011, the total tax on a carton of 200 cigarettes in Ontario was about $\$ 49$, which is the sum of the provincial tobacco tax $(\$ 24.70)$, the federal tobacco tax (\$17.00) and the harmonized sales tax (including a federal component of $\$ 3.19$ and a provincial component of \$5.10). ${ }^{8}$ Under Canadian law, cigarettes purchased by First Nations people on reserves are exempt from federal sales tax and provincial tobacco tax; cigarettes sold to non-First Nations people on reserves are subject to all 3 taxes, but enforcement is often lacking. ${ }^{6}$ By evading all or part of the taxes, cigarettes sold to non-First Nations people on reserves can cost much less than they would on the standard market: 200 reserve-made generic cigarettes retail for as little as \$6, whereas the standard market price ranges from
Competing interests: None declared.

This article has been peer reviewed.

Correspondence to: Graham Mecredy, graham.mecredy@camh.ca

CMAJ 2013. DOI:10.1503 /cmaj.111861 
$\$ 75$ to $\$ 90 .{ }^{6}$ We hypothesize that this extreme price gap affects quitting behaviour.

Smoking cessation is a central tenet in provincial, ${ }^{9}$ federal ${ }^{10}$ and international tobacco control efforts. ${ }^{11}$ For this reason, it is important to understand the impact the use of contraband tobacco has on smoking cessation outcomes. We assessed the association between contraband tobacco use and smoking cessation outcomes using prospective data from a population-based cohort of people who smoke.

\section{Methods}

\section{Study population and design}

We used data from the Ontario Tobacco Survey, a regionally stratified, random telephone survey of residents of Ontario aged 18 years or older. ${ }^{12,13}$ The survey did not capture data on First Nations status. A population-representative sample of adults who had smoked within the previous 6 months was recruited and recontacted semiannually for up to 3 years. Overall, 4504 people completed a baseline survey between July 2005 and June 2008 with a response rate of $61 \%$; $^{12}$ the 12 -month retention rate was $80 \% \cdot{ }^{13}$ Research ethics approval for the survey was obtained from the University of Toronto and the University of Waterloo.

From respondents to the survey, we selected those who met the following eligibility criteria: self-reported smoker, smoked 100 or more cigarettes during their lifetime, had smoked in the preceding 30 days at baseline, provided data on cigarette brand at baseline, and cessation outcome data available at both the 6-month and 1year follow-up interviews.

\section{Primary exposure variable}

Data on cigarette brand were based on responses to the question "Can you tell me the exact brand of cigarettes that you usually smoke, including the size and type?" A respondent's usual brand of cigarettes was initially categorized as premium, discount or contraband, according to a list of discount cigarette brands (typically $\$ 10-\$ 12$ less per carton than premium) $)^{14}$ and known contraband cigarette brands. ${ }^{15}$ After initial data analysis, people who smoked premium and discount cigarettes were combined, because there was no significant difference between these groups with respect to the association of brand with smoking cessation outcomes (data not shown). People who smoked contraband cigarettes formed 2 groups: those who reported usually smoking a known contraband brand (e.g., Putter's, DK's, Sago, Gold Leaf); and those who reported usually smoking a reserve brand, without specifying a brand name (e.g., "reserve ciga- rettes," "native cigarettes," "rollies" [unmarked bags of cigarettes]). Respondents who reported contraband as their usual brand at 2 consecutive follow-up interviews were classified as persistent users of contraband tobacco.

\section{Outcome measures}

Our primary outcome measure was smoking cessation, measured as attempts to quit, 30-day cessation and long-term cessation. We defined an attempt to quit as any self-identified attempt to stop smoking cigarettes during follow-up, determined from responses to the question "In the past 6 months, did you try to quit smoking completely"? In addition, respondents who reported no longer smoking at the time of their follow-up interview were classified as having made an attempt to quit. We defined 30-day smoking cessation as any attempt to quit during follow-up that lasted at least 30 days, determined from responses to the question "In the past 6 months, what was the longest amount of time you were able to reduce your smoking"? We also included respondents who were smoke-free at the time of follow-up and who had last smoked more than 1 month before the interview. We measured the attempt to quit and 30day cessation variables over 6-month and 1-year follow-up periods. We defined long-term cessation as abstinence for 6 months or more, which we determined from the 1-year follow-up interview.

\section{Covariates}

Potential covariates included various smoking behaviours: usually purchasing cigarettes on reserve, pack-year smoking history, heaviness of smoking index (a modified Fagerstrom score for nicotine dependence, based on time to first cigarette each day and number of cigarettes per day), ${ }^{16}$ intention to quit, lifetime attempts to quit and perceived addiction, as well as having support to quit, having someone who might hinder quitting and exposure to smoking in the home. Use and knowledge of cessation resources included previous use of pharmacotherapy (e.g., nicotine replacement therapy) and counselling, as well as negative beliefs regarding the cost and accessibility of pharmacotherapy and counselling. Demographic characteristics included age, sex, education, rurality, proportion of neighbourhood below the lowincome cut-off and survey year.

\section{Statistical analysis}

We compared the baseline characteristics of respondents who smoked contraband cigarettes with those who smoked premium or discount cigarettes using the $\chi^{2}$ statistic. We used unadjusted and multivariable logistic regression models (adjusted for all covariates) to examine the 
association between use of contraband tobacco and smoking cessation outcomes; our models were fit for both 6- and 12-month follow-up. We calculated population-weighted estimates using expansion weights corresponding to age and sex based on population estimates for Ontario from the 2006 census. We conducted a sensitivity analysis using multiple imputation to measure the impact of missing data. Similar models were fit to examine the relationship between persistent use of contraband tobacco (i.e., reporting usually smoking contraband cigarettes in 2 consecutive interviews) and cessation outcomes. We converted odds ratios (ORs) obtained from logistic models to relative risks (RRs) using methods proposed by Zhang and $\mathrm{Yu}^{17}$

\section{Results}

Of the 4504 respondents who completed the baseline survey, 2786 met our eligibility criteria (Figure 1). Of these respondents, 365 (13.1\%) usually smoked contraband cigarettes. A subanalysis of respondents for whom cigarette price data were available $(n=881)$ showed that people who smoked premium and discount cigarettes paid an average of $\$ 6.30-\$ 10.30$ per 20 cigarettes (1 pack), whereas those who smoked contraband tobacco paid only $\$ 2.50$. Compared with people who smoked premium or discount cigarettes, those who smoked contraband cigarettes were more likely to be older than 45 years of age, female, have a low level of education, live in a rural area and usually purchase cigarettes on reserve (Table 1). Furthermore, people who smoked contraband cigarettes had higher levels of nicotine dependence, had been smoking for longer (in terms of pack-year history), had no intention to quit, perceived themselves to be very addicted, had previously used pharmacotherapy to stop smoking and were exposed to smoking in the home (Table 1).

During the first 6 months, $18.9 \%$ of people who smoked contraband tobacco made an attempt to quit, compared with $30.1 \%$ of those who used premium or discount tobacco (Table 2). People who smoked contraband cigarettes were significantly less likely to make an attempt to quit during both the 6- and 12-month follow-up periods in our unadjusted models (Table 2). However, when adjusted for covariates, these associations were not statistically significant (RR 0.74, 95\% confidence interval [CI] 0.43-1.20, for 6-mo follow-up; RR 0.93, 95\% CI $0.63-1.26$, for $1-y r$ follow-up). Covariates that remained independently associated with attempts to quit at 1 year were age, survey year, heaviness of smoking index, intention to quit, number of lifetime attempts to quit, support for quitting, exposure to smoking in the home and beliefs regarding the accessibility of pharmacotherapy (Appendix 1, available at www.cmaj.ca/lookup /suppl/doi:10.1503/cmaj.111861/-/DC1). During the first 6 months, $4.3 \%$ of people who smoked contraband cigarettes achieved 30-day cessation compared with $10.7 \%$ of people who smoked premium or discount brands. After adjusting for covariates, people who smoked contraband cigarettes at baseline were about $80 \%$ (RR 0.23 , 95\% CI 0.09-0.61) and 70\% (RR 0.30, 95\% CI 0.14-0.61) less likely to report a period of 30day abstinence at the 6-month and 1-year followup, respectively (Table 2). Covariates that remained independently associated with 30-day cessation at 1-year included usually buying tobacco on reserve, heaviness of smoking index, intention to quit, perceived addiction and exposure to smoking in the home (Appendix 1). Smoking contraband tobacco was not associated with long-term cessation (adjusted RR 0.24, 95\% CI 0.04-1.34; Table 2). Our sensitivity analysis showed that missing data did not affect the associations we saw (data not shown).

Among people who smoked premium/discount

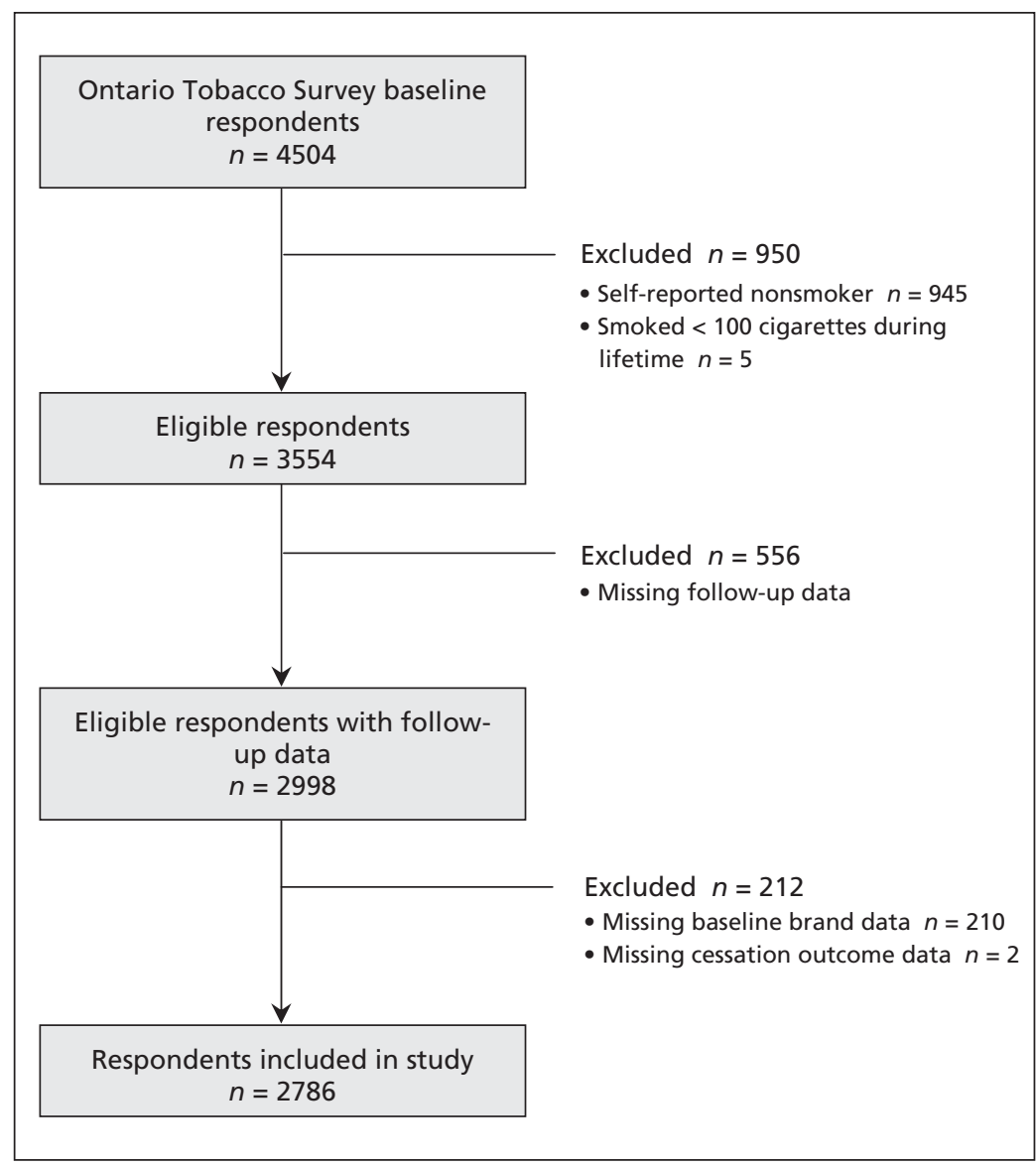

Figure 1: Selection of respondents to the Ontario Tobacco Survey for inclusion in the study. 
tobacco at baseline, there was no significant difference in attempts to quit or 30-day cessation among those who switched to contraband ciga- rettes compared with those who did not switch (Table 3). People who persistently used contraband tobacco, compared with those who persis-

Table 1: Baseline characteristics of respondents by usual brand of tobacco

\begin{tabular}{|c|c|c|c|}
\hline Characteristic & \multicolumn{2}{|c|}{ Usual brand of tobacco } & $p$ value $\neq$ \\
\hline $18-29$ & $401(23.3)$ & $40(12.8)$ & \\
\hline $30-44$ & $777 \quad(34.3)$ & $108(34.1)$ & \\
\hline Male sex & $1066(53.4)$ & $140(44.7)$ & 0.04 \\
\hline Education & & & 0.002 \\
\hline Less than high school & $382(14.1)$ & $90 \quad(23.2)$ & \\
\hline Completed high school and some college or university & $1057 \quad(42.7)$ & $132(35.7)$ & \\
\hline Completed college or university & $979(43.1)$ & $143(41.0)$ & \\
\hline 2005 & $418(20.1)$ & $51(14.6)$ & \\
\hline 2006 & $839(37.1)$ & $99(28.3)$ & \\
\hline 2007 & $798(29.9)$ & $131(33.9)$ & \\
\hline 2008 & $366(12.9)$ & $84(23.2)$ & \\
\hline \multicolumn{4}{|l|}{ Smoking } \\
\hline Usually buy cigarettes on reserve & $115 \quad(3.6)$ & $301(90.4)$ & $<0.001$ \\
\hline History, pack-years & 22.4 & 31.9 & $<0.001$ \\
\hline Heaviness of smoking index & & & $<0.001$ \\
\hline Low & $1175 \quad(52.5)$ & 83 (24.7) & \\
\hline Moderate & $966(38.8)$ & $196(54.7)$ & \\
\hline Not at all addicted & $147 \quad(7.3)$ & $9 \quad(3.1)$ & \\
\hline Somewhat addicted & $680(32.1)$ & $63(19.0)$ & \\
\hline Very addicted & $1586(60.7)$ & $292(77.9)$ & \\
\hline Have someone to support quiting & 2051 (86.6) & $280(81.4)$ & 0.02 \\
\hline Have someone who would make quitting difficult & 1008 (45.6) & $174(47.5)$ & 0.6 \\
\hline Other people smoke in the home & $1266(44.0)$ & $255(67.8)$ & $<0.001$ \\
\hline \multicolumn{4}{|l|}{ Use/knowledge of smoking cessation resources } \\
\hline Previous use of pharmacotherapy & $1412(53.2)$ & $246(63.2)$ & 0.009 \\
\hline Perceive cost of pharmacotherapy to be high & $970(36.9)$ & $193(53.0)$ & $<0.001$ \\
\hline Perceive pharmacotherapy to be difficult to access & $107 \quad(3.9)$ & $24 \quad(5.3)$ & 0.3 \\
\hline Previous use of counselling & $156 \quad(5.9)$ & $23 \quad(3.7)$ & 0.07 \\
\hline Perceive cost of counselling to be high & $692(27.8)$ & $116(28.8)$ & 0.8 \\
\hline Perceive counselling to be difficult to access & $362(12.7)$ & $67(14.1)$ & 0.5 \\
\hline
\end{tabular}


Table 2: Association between type of cigarette smoked at baseline and cessation outcomes at 6 months and 1 year

\begin{tabular}{|c|c|c|c|}
\hline \multirow{2}{*}{$\begin{array}{l}\text { Cessation outcomes at } 6 \mathrm{mo} \text { and } \\
1 \mathrm{yr} \text {; type of cigarette }\end{array}$} & \multirow[b]{2}{*}{ Respondents, \%*† } & \multicolumn{2}{|c|}{$\operatorname{RR}(95 \% \mathrm{Cl})$} \\
\hline & & Unadjusted & Adjusted $¥$ \\
\hline \multicolumn{4}{|l|}{ Attempt to quit } \\
\hline \multicolumn{4}{|l|}{ At 6 mo } \\
\hline Premium/discount & 30.1 & 1.00 (ref) & 1.00 (ref) \\
\hline Contraband & 18.9 & $0.63(0.45-0.85)$ & $0.74(0.43-1.20)$ \\
\hline \multicolumn{4}{|l|}{ At $1 \mathrm{yr}$} \\
\hline Premium/discount & 43.3 & 1.00 (ref) & 1.00 (ref) \\
\hline Contraband & 27.1 & $0.63(0.49-0.79)$ & $0.93(0.63-1.26)$ \\
\hline \multicolumn{4}{|l|}{ 30-day cessation } \\
\hline \multicolumn{4}{|l|}{ At $6 \mathrm{mo}$} \\
\hline Premium/discount & 10.7 & 1.00 (ref) & 1.00 (ref) \\
\hline Contraband & 4.3 & $0.40(0.18-0.86)$ & $0.23(0.09-0.61)$ \\
\hline \multicolumn{4}{|l|}{ At $1 \mathrm{yr}$} \\
\hline Premium/discount & 17.9 & 1.00 (ref) & 1.00 (ref) \\
\hline Contraband & 8.0 & $0.45(0.27-0.72)$ & $0.30(0.14-0.61)$ \\
\hline \multicolumn{4}{|l|}{ Long-term cessation } \\
\hline Premium/discount & 4.0 & 1.00 (ref) & 1.00 (ref) \\
\hline Contraband & 1.6 & $0.39(0.15-1.00)$ & $0.24(0.04-1.34)$ \\
\hline \multicolumn{4}{|c|}{$\begin{array}{l}\text { Note: } \mathrm{Cl}=\text { confidence interval, ref }=\text { reference category, } \mathrm{RR}=\text { relative risk. } \\
\text { *Sample sizes for unadjusted analyses were } 2786 \text { overall, } 2421 \text { for premium/discount brands, and } 365 \text { for contraband cigarettes; } \\
\text { sample sizes for adjusted analyses were } 2310,2029 \text { and } 281 \text {, respectively. } \\
\text { tPopulation-weighted estimates. } \\
\text { fAdjusted for all covariates listed in Table } 1 .\end{array}$} \\
\hline
\end{tabular}

Table 3: Switching between premium or discount and contraband cigarettes as a predictor of cessation outcomes during 1-year follow-up period, by type of cigarette at baseline

\begin{tabular}{|c|c|c|c|}
\hline \multirow{2}{*}{$\begin{array}{l}\text { Outcome; type of cigarette at } \\
\text { baseline }\end{array}$} & \multirow[b]{2}{*}{ Respondents, \%*† } & \multicolumn{2}{|c|}{ RR $(95 \% \mathrm{Cl})$} \\
\hline & & Unadjusted & Adjusted $\neq$ \\
\hline \multicolumn{4}{|l|}{ Quit attempt } \\
\hline \multicolumn{4}{|l|}{ Premium/discount } \\
\hline No switching brands & 38.5 & 1.00 (ref) & 1.00 (ref) \\
\hline Switched to contraband & 30.8 & $0.80(0.55-1.11)$ & $0.80(0.53-1.14)$ \\
\hline \multicolumn{4}{|l|}{ Contraband } \\
\hline No switching brands & 24.4 & 1.00 (ref) & 1.00 (ref) \\
\hline Switched to premium/discount & 29.3 & $1.20(0.56-2.14)$ & $1.49(0.51-2.86)$ \\
\hline \multicolumn{4}{|l|}{ 30-day cessation§ } \\
\hline \multicolumn{4}{|l|}{ Premium/discount } \\
\hline No switching brands & 10.9 & 1.00 (ref) & 1.00 (ref) \\
\hline Switched to contraband & 6.5 & $0.60(0.23-1.46)$ & $0.92(0.28-2.61)$ \\
\hline \multicolumn{4}{|c|}{$\begin{array}{l}\text { Note: } \mathrm{Cl}=\text { confidence interval, } \text { ref }=\text { reference category, } \mathrm{RR}=\text { relative risk. } \\
\text { *Sample sizes for unadjusted analyses were } 2471 \text { overall, } 2143 \text { for premium/discount brands, and } 328 \text { for contraband cigarettes } \\
\text { sample sizes for adjusted analyses were } 2068,1813 \text { and } 255 \text {, respectively. The total number of people who switched brands was } \\
152 \text { for premium/discount and } 37 \text { for contraband. } \\
\text { †Population-weighted estimates. } \\
\text { fAdjusted for all covariates listed in Table } 1 \text {. } \\
\text { \$Because only } 1 \text { respondent switched from contraband to premium/discount cigarettes and reported a period of } 30 \text {-day } \\
\text { cessation, the contraband portion of the analysis was omitted. }\end{array}$} \\
\hline
\end{tabular}


tently used premium or discount brands, were less likely to attempt to quit in the subsequent 6 months (RR 0.53, 95\% CI 0.37-0.74) and achieve a period of 30-day abstinence (RR 0.38, 95\% CI 0.20-0.72); however, these relations were not significant in adjusted models (Table 4).

We also examined the association between price and cessation outcomes in a subset of 881 participants for whom price data were available. After adjusting for covariates, a $\$ 1.00$ increase in the price of a pack of cigarettes was associated with an increase in long-term cessation (adjusted RR 1.12, 95\% CI 1.01-1.25) (Appendix 2, available at www.cmaj.ca/lookup/suppl/doi:10.1503 /cmaj.111861/-/DC1).

\section{Interpretation}

Our results suggest that smoking contraband cigarettes is negatively correlated with 30-day smoking cessation. We posit that the substantial price gap between premium or discount and contraband cigarettes is the reason for this correlation. Using the consumer demand theory, which suggests that consumption decreases as price increases, ${ }^{18}$ and the strong evidence linking high tobacco prices to reduced consumption at the population level, ${ }^{1,2}$ the correlation between the low price of contraband tobacco and poorer smoking cessation is logical. We did not see the same relation for attempts to quit, which further supports the notion that attempts to quit and successful smoking cessation are influenced by different factors. ${ }^{19-23}$

We did not see significant associations between cessation outcomes among people who smoked premium or discount tobacco who subsequently switched to contraband cigarettes, or among people who smoked contraband tobacco who switched to premium or discount brands.

Table 4: Persistent use of premium or discount, or contraband tobacco as a predictor of cessation outcomes during the 6-month follow-up period

\begin{tabular}{|llll|}
\hline \multirow{2}{*}{$\begin{array}{l}\text { Outcome; type of } \\
\text { cigarette }\end{array}$} & Respondents, \%* + & Unadjusted & Adjusted $\neq$ \\
\hline Attempt to quit & & & \\
\hline Premium/discount & 27.0 & 1.00 (ref) & 1.00 (ref) \\
\hline Contraband & 14.4 & $0.53(0.37-0.74)$ & $1.00(0.51-1.70)$ \\
\hline 30-day cessation & & & \\
\hline Premium/discount & 8.4 & $1.00($ ref) & $1.00($ ref $)$ \\
\hline Contraband & 3.2 & $0.38(0.20-0.72)$ & $0.55(0.21-1.37)$ \\
\hline
\end{tabular}

Note: $\mathrm{Cl}=$ confidence interval, ref = reference category, $\mathrm{RR}=$ relative risk.

*Sample sizes for unadjusted analyses were 2282 overall, 1991 for premium/discount brands and 291 for contraband cigarettes; sample sizes for adjusted analyses were 1910, 1682 and

228, respectively.

tPopulation-weighted estimates.

$\ddagger$ Adjusted for all covariates listed in Table 1.
However, because only 152 people who smoked premium or discount tobacco and 37 people who smoked contraband tobacco switched brands, the power to detect associations was quite low. Further investigation into brand switching and cessation outcomes is warranted.

From a stages-of-change perspective ${ }^{24}$ it appears that people who smoke premium/ discount tobacco are more likely to be in the contemplation/preparation stage, as $40 \%$ intend to quit (v. $27 \%$ for contraband tobacco). Although the use of contraband tobacco may not hinder the transition to the action stage (as evidenced by the similarity in attempts to quit), it may cause regression from the action stage (as evidenced by poorer 30-day cessation).

We identified disparities in the use of contraband cigarettes, suggesting that tailored tobacco control policies may be warranted. Our results also support action to reduce the availability of contraband tobacco products in the market. However, the required steps to accomplish this task are not clear-cut. As an essential part of addressing contraband tobacco, the World Health Organization (WHO) Framework Convention on Tobacco Control calls for international cooperation in controlling smuggling, legislation to prevent illicit trade by controlling the production and distribution of tobacco, and the development of a tracking and tracing system to prevent the diversion of cigarettes away from the legal distribution system. ${ }^{11}$ In addition, WHO recognizes

the need to take measures to promote the participation of indigenous individuals and communities in the development, implementation and evaluation of tobacco control programmes that are socially and culturally appropriate to their needs and perspectives. ${ }^{11}$

A successful approach cannot rely solely on increased enforcement; ${ }^{25}$ it must also involve respectful engagement with First Nations communities, as well as consideration of tobacco control within the larger public health concerns of First Nations people.

Previous research has found that use of lowtax or untaxed cigarettes was associated with fewer attempts to quit ${ }^{26,27}$ and reduced the likelihood of smoking cessation..$^{28}$ A study conducted in 2 US counties located near American Indian reservations found that smokers who bought cigarettes on reserve were half as likely to attempt to quit, with a trend toward decreased cessation. ${ }^{26}$ Previous literature using data from the International Tobacco Control study found that people purchasing low-tax or untaxed cigarettes were about $30 \%$ less likely to report attempting to quit, with no effect found on cessation. ${ }^{27} \mathrm{~A}$ more recent International Tobacco Control study found 
that people purchasing low or untaxed cigarettes were less likely to have quit after 1 year. ${ }^{28}$ Although there is no consensus in the literature that smoking low-tax or untaxed cigarettes is consistently correlated with both attempts to quit and cessation, there appears to be a pattern of negative correlation with quitting behaviours.

Hyland and colleagues looked at contraband tobacco use; however, they were limited in geographic scope because they studied only 2 counties. ${ }^{26}$ Research from the International Tobacco Control study focused on low-tax or untaxed sources of tobacco, which was defined as cigarettes purchased from a wide variety of sources, including military commissaries, Native reservations, duty-free shops, out of state or country, by telephone, over the Internet, friends or relatives, and independent sellers. ${ }^{27,28}$ In contrast, our population-based study focused solely on contraband tobacco coming both directly and indirectly from First Nations reserves, which continues to be a major issue in Canada. Gathering information on cigarette brands enabled us to capture data not only from people who purchased their contraband cigarettes on reserve, but also from those who obtained known contraband brands through other channels of distribution, resulting in a more representative population of people who use contraband tobacco.

\section{Limitations}

Given its illegality, respondents to the survey may have underreported their use of contraband tobacco. Our estimates of contraband tobacco use could also be overstated; this would arise if data from First Nations people were captured in our study and categorized as being from users of contraband tobacco, despite their consumption of cigarettes purchased on reserve being legal. Although First Nations people make up only $2 \%$ of the Ontario population, ${ }^{29}$ their smoking rates are markedly higher than those of the general population; ${ }^{30}$ because our inclusion criteria included smoking status, the chance of inclusion for First Nations people is slightly higher than for the general population. Finally, a lack of data on comorbidities, including concurrent mental health issues and addictions, was also a concern.

\section{Conclusion}

The availability of low-cost contraband cigarettes may attenuate public health efforts to reduce the prevalence of smoking through the implementation of high tobacco prices and taxation. Given that smoking contraband cigarettes has a negative influence on cessation outcomes, tobacco control policies that reduce or eliminate access to contraband tobacco may have a sub- stantial impact on population-level quitting behaviour. To optimize the public health benefits of current and future tobacco control initiatives, innovative solutions that address the accessibility of contraband tobacco are required.

\section{References}

1. Chaloupka FJ, Warner KE. The economics of smoking. In: Culyer AJ, Newhouse JP, editors. Handbook of health economics. New York (NY): Elsevier; 2000. p. 1539-1627.

2. Gruber J, Sen A, Stabile M. Estimating price elasticities when there is smuggling: the sensitivity of smoking to price in Canada. J Health Econ 2003;22:821-42.

3. Chaloupka FJ, Cummings KM, Morley CP, et al. Tax, price and cigarette smoking: evidence from the tobacco documents and implications for tobacco company marketing strategies. Tob Control 2002;11(Suppl 1):I62-72.

4. Joossens L, Chaloupka FJ, Merriman D, et al. Issues in smuggling of tobacco products. In: Jha P, Chaloupk FJ, editors. Tobacco control in developing countries. London (UK): Oxford University Press; 2000. p. 394-406.

5. Physicians for a Smoke Free Canada. The Canadian tobacco marketplace: estimating the volume of contraband sales of tobacco in Canada, 2010. Ottawa (ON): Available: www.smoke-free .ca/eng_research/pscresearch_papers.htm (accessed 2012 Jan. 14)

6. 2008 contraband tobacco enforcement strategy, 2008. Ottawa (ON): Royal Canadian Mounted Police. Available: www.rcmp-grc .gc.ca/pubs/tobac-tabac/tobacco-tabac-strat-2008-eng.htm (accessed 2012 Jan. 14)

7. Luk R, Cohen JE, Ferrence R, et al. Prevalence and correlates of purchasing contraband cigarettes on First Nations reserves in Ontario, Canada. Addiction 2009;104:488-95.

8. Tobacco taxes: monitoring update, 2011. Toronto (ON): Ontario Tobacco Research Unit; 2011. Available: http://otru.org/2011 -monitoring-report-tobacco-taxes-april/ (accessed 2012 Jan. 14).

9. Ontario Ministry of Health and Long-term Care. Building on our gains, taking action now: Ontario's tobacco control strategy for 2011-2016. Ottawa (ON): The Ministry; 2010. Available: www .mhp.gov.on.ca/en/smoke-free/TSAG\%20Report.pdf (accessed 2013 Jan. 14)

10. Federal tobacco control strategy, 2009. Ottawa (ON): Health Canada; 2009. Available: www.hc-sc.gc.ca/hc-ps/tobac-tabac/about -apropos/role/federal/strateg-eng.php (accessed 2013 Jan. 14).

11. World Health Organization. Framework convention on tobacco control. Geneva (Switzerland): The Organization; 2003. Available: www.who.int/tobacco/framework/WHO_FCTC_english .pdf (accessed 2011 Oct. 27).

12. Diemert L, Victor JC, Chaiton M, et al. Ontario tobacco survey technical report 1: baseline data. Toronto $(\mathrm{ON})$ : Ontario Tobacco Research Unit; 2010.

13. Diemert L, Victor JC, Chaiton M, et al. Ontario tobacco survey technical report 2: six and twelve month data. Toronto $(\mathrm{ON})$ : Ontario Tobacco Research Unit; 2010.

14. Backgrounder on the Canadian tobacco industry and its market: 2007-08 edition, March 2008. Ottawa (ON): Non-Smokers' Rights Association; 2008. Available: www.nsra-adnf.ca/cms /index.cfm?group_id=1513 (accessed 2013 Jan. 13).

15. Diemert LM, Cohen JE, Bondy SJ, et al. Smoking low-cost cigarettes: disparities evident. Can J Public Health 2011;102: 73-4.

16. Heatherton T F, Kozlowski L T, Frecker R C, et al. Measuring the heaviness of smoking: using self-reported time to the first cigarette of the day and number of cigarettes smoked per day. Br J Addict 1989;84:791-9.

17. Zhang J, Yu KF. What's the relative risk? A method of correcting the odds ratio in cohort studies of common outcomes. JAMA 1998;280:1690-1.

18. Bickel WK, Yi R, Mueller ET, et al. The behavioral economics of drug dependence: towards the consilience of economics and behavioral neuroscience. Curr Top Behav Neurosci 2010;3:319-41.

19. Borland R., Yong H. H., Balmford J., et al. Motivational factors predict quit attempts but not maintenance of smoking cessation: findings from the International Tobacco Control Four Country Project. Nicotine Tob Res 2010;12(Suppl):S4-11.

20. Diemert LM, Bondy SJ, Brown KS, et al. Young adult smoking cessation: predictors of quit attempts and abstinence. Am J Public Health 2013; Jan. 17

21. Hyland A, Borland R, Li Q, et al. Individual-level predictors of cessation behaviours among participants in the International Tobacco Control (ITC) Four Country Survey. Tob Control 2006; 15(Suppl 3):iii83-94 
22. West R, McEwen A, Bolling K, et al. Smoking cessation and smoking patterns in the general population: a 1-year follow-up. Addiction 2001;96:891-902.

23. Zhou X, Nonnemaker J, Sherrill B, et al. Attempts to quit smoking and relapse: factors associated with success or failure from the ATTEMPT cohort study. Addict Behav 2009;34:365-73.

24. DiClemente CC, Prochaska JO, Fairhurst S, et al. The process of smoking cessation: an analysis of precontemplation, contemplation and preparation stages of change. J Consult Clin Psychol 1991;59:295-304

25. Brzozowski J, Taylor-Butts A, Johnson S. Victimization and offending among the Aboriginal population in Canada. Ottawa (ON): Statistics Canada; 2006. Rep. no. 85-002-XIE.

26. Hyland A, Higbee C, Li Q, et al. Access to low-taxed cigarettes deters smoking cessation attempts. Am J Public Health 2005;95: 994-5.

27. Hyland A, Laux FL, Higbee C, et al. Cigarette purchase patterns in four countries and the relationship with cessation: findings from the International Tobacco Control (ITC) Four Country Survey. Tob Control 2006;15(Suppl 3):iii59-64.

28. Licht AS, Hyland AJ, O'Connor RJ, et al. How do price minimizing behaviours impact smoking cessation? Findings from the International Tobacco Control (ITC) Four Country Survey. Int $J$ Environ Res Public Health 2011;8:1671-91.

29. Aboriginal peoples highlight tables, 2006 census. Ottawa (ON): Statistics Canada; 2008. Available: www12.statcan.ca/english/ census06/data/highlights/aboriginal/index.cfm?Lang=E (accessed 2011 Oct. 27).

30. Wardman AED, Khan NA. Registered Indians and tobacco taxation: A culturally-appropriate strategy? Can J Public Health 2005;96:451-3.

Affiliations: From the Ontario Tobacco Research Unit (Mecredy, Diemert, Cohen), Toronto, Ont.; Northern Medical
Program (Callaghan), University of Northern British Columbia, Prince George, BC; Dalla Lana School of Public Health (Cohen), University of Toronto, Toronto, Ont.; and the Institute for Global Tobacco Control (Cohen), Johns Hopkins Bloomberg School of Public Health, Baltimore, Md.

Contributors: Graham Mecredy and Lori Diemert were involved in the design of the study, drafting the manuscript and the analysis and interpretation of the data. Russell Callaghan was involved in the analysis and interpretation of the data. Joanna Cohen was involved in the design of the study and the interpretation of the data. All of the authors revised the manuscript for important intellectual content and approved the final version submitted for publication.

Funding: This study was conducted by the Ontario Tobacco Research Unit using data from the Ontario Tobacco Survey, an initiative of the unit, which receives funding from the Ontario Ministry of Health and Long-term Care. The Ontario Ministry of Health and Long-term Care had no role in the design of the study, the collection, analysis or interpretation of data, the writing of the report or the decision to submit the article for publication.

Acknowledgments: The authors acknowledge Dr. Susan Bondy, Dr. Roberta Ferrence, Dr. K. Stephen Brown, Dr. John Garcia, Dr. Paul McDonald, Dr. Robert Schwartz, Dr. Peter Selby, Mr. Charles Victor, Dr. Michael Chaiton and the Survey Research Centre at the University of Waterloo for their contributions to the Ontario Tobacco Survey. The authors also thank Ms. Rita Luk for her significant contributions coding cigarette brand data. 